\title{
OPTIMISM AND PESSIMISM AND THEIR RELATIONSHIP TO THE CHARACTERISTICS OF INTERMEDIATE SCHOOL FEES
}

Kanaan Ghadhban Habib AL-SHAWHANI*

Art Education Department, College of Fine Arts, Baghdad University, Iraq

\begin{abstract}
Those who choose educational and psychological sciences as a field of specialization must realize the need for the impact of expectation linked to optimism and pessimism that leave their mark on young people in the prime of their lives, especially in the middle school stage, and the need to know the existence of these two features and their degree in them and through means that do not arouse great interest in them, especially since this group The age in which the human being is more sensitive, which must be dealt with cautiously, and therefore methods such as questionnaires and questions are embarrassing, and the best alternative to them is the projective drawings that you can obtain through the art education lesson, but we must first: get to know the characteristics that appear in the drawings of optimists and pessimists Each side and upon it the search required the help of two tools.

Keywords

Optimism, Pessimism, Relationship, Characteristics, Intermediate, School Fees.
\end{abstract}

\section{Introduction}

A tool that reveals the two features of (optimism - pessimism .. a tool for analyzing intermediate school students' fees according to the above characteristics of the Baghdad governorate. The researcher has built a tool that identifies my feature (optimism - pessimism) for his research as the number of members of the scale sample reached one student of the second intermediate grade students. The psychometric properties) of the measurement items by testing and the internal consistency factor by choosing the correlation coefficient (Pearson) and checking the psychometric properties of the whole scale (truthfulness, stability) and finding the percentage of error in the scale degree (standard error), and the researcher also used the graphic analysis tool that we built (Al Bayati 2004) to find it. With the method of content analysis required to achieve this research, the tool was destroyed from three main areas that included a secondary field from which branched out a category that included (especially for drawing, and after the researcher verified its validity And its stability, the researcher, together with external analysts, analyzed a sample of the fees if the reliability parameters ranged between $(0,786-0,842)$ and all the transactions were statistically significant in the level and the two tools were applied to the basic research sample of which the number of individuals reached (160) students. The measurement tool called (optimism - pessimism) on their responses to the questions, and their drawings were subjected to analysis of the fee tool.

The following results were shown:

* Corresponding author: web.admin@ cofarts.uobaghdad.edu.iq 
1. The research showed that there are differences in the characteristics of the drawings among those with (optimism - pessimism) and the difference between their percentages was statistically significant at the level of $(0,05)$. 2 . The fees of those with optimism showed the existence of (26) special, and the fees of those with pessimism (27) attributes that obtained a percentage of $(50 \%)$ or more for each of them.

\section{First: The importance of research}

A: The mysterious problems of a person for which he does not know an explanation and is not able to confront them or get rid of them, are among the most troublesome problems that concern a person's feeling disturbing, as they affect his life, whether these effects are realistic or vague, despite Whoever lives in the shadow of the scientific and technological revolution that is supposed to have provided him with everything, but these vast civilizational achievements have carried with them many psychological troubles, represented by the elements of turmoil, anxiety, loss of a sense of security, threats and wars. Today, when we are at the dawn of the third millennium, we desperately need to study the personality of man more than ever, due to its importance in understanding his behavior in various aspects, so the increase in requirements and necessities. That burdened a person with pressures that contributed to the complication of his personality in one way or another, and therefore this personality must be understood in a way that reveals its effectiveness, performance and development in a way that ensures confronting various psychological phenomena that cause harm or limit the person's competence and reach an appropriate interpretation of its subjects in preparation for studying and then treating them, which are the subject of Expectation and its impact on human feelings and emotions, especially when it comes back to previous experience, as well as what these expectations are related to from a system, and a mechanism through which it works to confront the next situation, positively or negatively, And what goes back to the person's thinking pattern that leads to happy expectations that have a good effect in raising the morale of the individual. On the contrary, we find the discouragement resulting from a bad expectation that has negative and potentially destructive effects in some cases; this is what leads us to the topic (optimism pessimism that has occupied a person since the beginning of his self-awareness. The use of these two words (optimism - pessimism is not new) except that the interest in the two concepts And studying it in detail in the context of psychology did not happen in an organized manner until the end of the twentieth century Al-Ansari, 2000, p. 3), if optimism is associated with optimism and a positive expectation from which moral or material advice is hoped for. Accordingly, optimists focus on the positive aspects when making their judgments if they tend to Expanding mention of new aspects with regard to their judgments, they are summarized in 
mentioning the bad aspects, and they are often successful people, especially since a successful person tends to fill himself with points of success, starting with optimism and ending with diligence to achieve success. (Musa, D.T., p. 195), while a pessimist, on the contrary, tends to be pessimistic about grief and negative expectation of events associated with loss and failure, and pessimism tends to exaggerate it. The bad aspects when he asks for his opinion on a topic, while he is summarized in mentioning the good aspects of what is presented to him with judgment and evaluation of opinion (Asaad, 1986, p. 12). Moreover, the danger of pessimism lies in the fact that it rushes like a tidal wave to the intellectual content causing depression, (Beck (2000, p. 130), that the individual's pessimistic expectations, exaggerated and excessive in bliss, lead to seeing the future as an extension of the present and that deprivation and failure will extend forever, and he assumes that in the event that an intractable problem appears in the present time, it will remain so and he will not be able to find it Solution, or to somehow bypass it; This is confirmed by a number of psychologists, including the psychologist (Cattel) (Schlitz, 1983, p. 315).

In the social stratum that will have a basic role in planning, directing and production through the numbers of a conscious generation strong in its structure, morals, personality and knowledge that is aware of its heritage as an extension of the makers of the first civilizations, and this is only through setting up extension and educational programs and activities that can help in the growth of optimistic personality and limit From the pessimistic personality, and that training students in the qualities associated with optimism frees them from remaining stuck in the failure they may be exposed to and enables them to become full of energy and enthusiasm for the next field of performance (541. Snyder, 19994, p), and this requires first of all to measure the degree of these two traits when Students to help determine the appropriate type of programs and activities and their contents, Moreover, it gives the phenomenon an accurate description and facilitates comparison with it, and here is an issue that defines the positions of high school students and their views towards their future, whether through optimism or pessimism, is very important to activate their role and activate their spirit of innovation in preparation for their participation in the positive movement of society.

The education process has become its main goal in many countries is to develop the minds of its children and work to invest it and address everything that would hinder the achievement of its goals as it is the basic condition for the advancement of society. Therefore, the trend was to pay attention to the youth as they are the renewed flow that guarantees any nation its continuation and reshaping itself. Societies to benefit from every scientific achievement that can benefit education in achieving its sufficiency after studying and experimenting, and with 
these methods many scientific achievements have been introduced into the field of education and this has been demonstrated by a comprehensive revolution in various fields, including the field of work analysis, systems analysis and operations research, these areas, including psychology and education Technical

and they are among the pillars that interest in them increases, if radical and comprehensive developments were introduced to them, their importance was evident in the different stages of education, which contributed to achieving the message of education in its comprehensive sense in the modern era, refining behavior and integration in personality, which is only through four systems, which are biological, mental, social and emotional). They work together in an integrative manner (Daoud, 1991, p. 444).

The All Port described the traits as follows:

1. The main features: the personality of the individual is centered around it, including motives, dominant emotions, and salient features (traits with a tendency), or "genetic predisposition", and he becomes famous through the hysterical, exploitative introverted personality.

2. Central features: have a lesser influence on the behavior of the individual, but are very important.

3. Secondary features: They appear from time to time and do not have a significant effect on behavior. (Al 370: port, 1961, p), and that the two features of optimism and pessimism are among the secondary features of the hypothetical (port) divisions that he set.

\section{References}

1. Dawn (1983): Personal Theories, TR: Hamad Wali Al-Karbouli and Abdul-Rahman AlQaisi, Baghdad University Press, Iraq.

2. Al-Ani, Nizar Muhammad Saeed (1989): The Character, 1st Edition, House of General Cultural Affairs, Ministry of Culture and Information, Baghdad.

3. Ali, Intisar Haidar (2005): Optimism - Pessimism and their Relationship to Gender, Class, Specialization and Academic Achievement among Baghdad University Students (Unpublished Master Thesis, Ibn Rushd College of Education, University of Baghdad).

4. Faeq, Ahmad (1972): Entrances to General Psychology, The Anglo-Egyptian Library, Cairo.

5. Al-Kanani, Ibrahim Abdel-Hassan and Siham Saeed Naoum (1987): Legalizing Personal Preference over Baghdad University Students, Adab Al-Mustansiriya Magazine, Issue (15), Baghdad.

6. Lazarus, Richard (1981): The Character, translated by: Muhammad Ghoneim, The Egyptian Renaissance Library, Cairo. 
7. Muhammad Saeed, Abu Talib (19990) Technical Psychology, Mosul University Press, Ministry of Higher Education and Scientific Research, Iraq.

8. Mahmoud, Essam Naguib (2001), Dynamics of Behavior and Strategies for Controlling and Modifying it, Dar Al Baraka, Amman.

9. Malika, Louis Kamel, and others (1959): Character and Its Measurement, The Egyptian Renaissance Library, Cairo. (1968): A Personal Study by Drawing, 3rd Edition, The Egyptian Renaissance Library,

11. Moussa, Salama (DT): The Successful Person, Al-Gharib Publishing House, Cairo.

12. Al-Mayahi, Aad Mahmoud Hammadi (1989): Characteristics of adolescents' drawings and their relationship to some of their personal characteristics, (Unpublished Master Thesis, College of Fine Arts, University of Baghdad).

13. Nobler, Nathan (1987) The Dialogue of the Vision, translated by: Fakhri Khalil, AlMa'moon House for Translation and Publishing, Baghdad.

14. Hall, Calvin and Lindsay Gard (1978): Theories of Personality, 2nd Edition, translation: A Group of Translators, Dar Al-Shaya Publishing, General Authority for Books, Cairo.

15. All port E.w. (1961), patterned and grow wther, personality, new york, hill, 1. rinckartant and Winston. And arson, S.M.spielman, L.A. \& burgh

16. -J.A. (1992) "euture events schemes and 2. certainty about the future: automatically in depressives future-vent predictions." Journal of personality and social psychology vol. 63, 711-623,

17. Cattell, R.B. (1966) the scientific an alysis of personality Baltimore: penguin. 3. Cronbach, L.J. (1970) .essentials of psychological testing, new york, haper and 4. row publisher.

18. -Kell, G. (1955): the psychology of personality construets, new york,: Norton. 5.

19. Rania Essmat Muhammad Al-Sayed AL-QURBA, DEVELOPMENT OF THE SPECIAL NEEDS CHILD'S VISUAL PERCEPTION (VISUAL PERCEPTION OF THE UPPER PERSPECTIVE), International Journal of Humanities and Language Research, Vol. 1, No. 1, 2018, pp. 30-32.

Received: August 10, 2018

Accepted: October 28, 2018 